University of New Hampshire

University of New Hampshire Scholars' Repository

$10-2002$

\title{
Nonfamily Abducted Children: National Estimates and Characteristics.
}

\author{
David Finkelhor \\ University of New Hampshire - Main Campus, David.Finkelhor@unh.edu \\ Heather Hammer \\ Temple University \\ Andrea J. Sedlack \\ Westat, Inc.
}

Follow this and additional works at: https://scholars.unh.edu/ccrc

Part of the Criminology Commons

\section{Recommended Citation}

Finkelhor, David; Hammer, Heather and Sedlack, Andrea J. Nonfamily abducted children: National estimates and characteristics. Juvenile Justice Bulletin - NCJ196467, (pgs.1-16). Washington, DC: US Government Printing Office.

This Article is brought to you for free and open access by the Research Institutes, Centers and Programs at University of New Hampshire Scholars' Repository. It has been accepted for inclusion in Crimes Against Children Research Center by an authorized administrator of University of New Hampshire Scholars' Repository. For more information, please contact Scholarly.Communication@unh.edu. 
J. Robert Flores

OJJDP Administrator

\section{Nonfamily Abducted Children: National Estimates and Characteristics}

\author{
David Finkelhor, Heather Hammer, and \\ Andrea J. Sedlak
}

The words "missing child" call to mind tragic and frightening kidnappings reported in the national news. But a child can be missing for many reasons, and the problem of missing children is far more complex than the headlines suggest. Getting a clear picture of how many children become missing - and why —is an important step in addressing the problem. This series of Bulletins provides that clear picture by summarizing findings from the Second National Incidence Studies of Missing, Abducted, Runaway, and Thrownaway Children (NISMART-2). The series offers national estimates of missing children based on surveys of households, juvenile residential facilities, and law enforcement agencies. It also presents statistical profiles of these children, including their demographic characteristics and the circumstances of their disappearance.

This Bulletin presents results from the initial analysis of nonfamily abduction data collected by the Second National Incidence Studies of Missing, Abducted, Runaway, and Thrownaway Children (NISMART-2). The NISMART-2 studies spanned the years 1997 to $1999 .{ }^{1}$ All data in the individual component studies were collected to reflect a 12-month period. Because the vast majority of cases were from the studies concentrated in 1999, the annual period referred to in this Bulletin is 1999. 


\section{Key Findings}

During the study year, there were an estimated 115 stereotypical kidnappings, defined as abductions perpetrated by a stranger or slight acquaintance and involving a child who was transported 50 or more miles, detained overnight, held for ransom or with the intent to keep the child permanently, or killed.

In 40 percent of stereotypical kidnappings, the child was killed, and in another 4 percent, the child was not recovered.

There were an estimated 58,200 child victims of nonfamily abduction, defined more broadly to include all nonfamily perpetrators (friends and acquaintances as well as strangers) and crimes involving lesser amounts of forced movement or detention in addition to the more serious crimes entailed in stereotypical kidnappings.

Fifty-seven percent of children abducted by a nonfamily perpetrator were missing from caretakers for at least 1 hour, and police were contacted to help locate 21 percent of the abducted children.

Teenagers were by far the most frequent victims of both stereotypical kidnappings and nonfamily abductions.

Nearly half of all child victims of stereotypical kidnappings and nonfamily abductions were sexually assaulted by the perpetrator.

\section{Conceptualizing the Problem}

The controversy and confusion that have plagued efforts to estimate the number of children abducted by nonfamily perpetrators stem in part from ambiguities regarding the meaning of the term "abduction." Because the media focus on notorious crimes, such as the kidnappings of Samantha Runnion, Polly Klass, and Adam Walsh, child abduction is conventionally thought of as a life-threatening crime of substantial duration and distance involving strangers. However, as legally defined, an abduction can occur when a person is held against his or her will for a modest amount of time or moved even a short distance, which often occurs in the commission of other crimes. Estimates based solely on the legal definition of abduction would be unlikely to satisfy those wanting to know about the risk and nature of stereotypical kidnappings, nor would the stereotypical kidnapping estimates alone satisfy those concerned about the phenomenon of abductions in general.

To satisfy both needs, NISMART-2 provides information about nonfamily abductions using two definitions. The narrower concept of stereotypical kidnapping pertains to the more serious type of abduction perpetrated by a stranger or slight acquaintance in which a child is taken or detained overnight, transported a distance of 50 or more miles, held for ransom or with the intent to keep the child permanently, or killed. The broader concept of nonfamily abduction includes stereotypical kidnappings but also includes less serious nonfamily abductions involving the movement of a child using physical force or threat, the detention of a child for a substantial period of time (at least 1 hour) in a place of isolation using threat or physical force, or the luring of a child

\section{Defining Nonfamily Abduction and Related Terms}

- Nonfamily abduction: (1) An episode in which a nonfamily perpetrator takes a child by the use of physical force or threat of bodily harm or detains the child for a substantial period of time (at least 1 hour) in an isolated place by the use of physical force or threat of bodily harm without lawful authority or parental permission, or (2) an episode in which a child younger than 15 or mentally incompetent, and without lawful authority or parental permission, is taken or detained or voluntarily accompanies a nonfamily perpetrator who conceals the child's whereabouts, demands ransom, or expresses the intention to keep the child permanently.

- Stereotypical kidnapping: A nonfamily abduction perpetrated by a slight acquaintance or stranger in which a child is detained overnight, transported at least 50 miles, held for ransom or abducted with intent to keep the child permanently, or killed.

- Stranger: A perpetrator whom the child or family do not know, or a perpetrator of unknown identity.

- Slight acquaintance: A nonfamily perpetrator whose name is unknown to the child or family prior to the abduction and whom the child or family did not know well enough to speak to, or a recent acquaintance who the child or family have known for less than 6 months, or someone the family or child have known for longer than 6 months but seen less than once a month. 
younger than 15 years old for purposes of ransom, concealment, or intent to keep permanently. (Nonfamily abduction and related terms are defined more fully in the sidebar on page 2 .)

Despite confusion about the meaning of abduction and the impression conveyed by notorious cases, an abduction does not necessarily imply that a child is missing. For example, a child can be abducted on the way home from school, dragged into a remote area, sexually assaulted, and released without being missed by a caretaker or reported as missing to any law enforcement agency. Even in more serious or lengthier stereotypical kidnappings, the victim will not qualify as a missing child if no one notices the child's absence or if the discovery of the child's body is the first evidence of the episode. Thus, the current study counted the child victims of nonfamily abductions who were not missing as well as those who were. (See Examples of NISMART-2 Nonfamily Abductions, page 4.)

The term "missing" itself has somewhat different meanings in different contexts. NISMART-2 characterized two types of missing children: "caretaker missing" children, who were missing from their caretakers whether or not those caretakers alerted any authority about the situation, and "reported missing" children, who were reported to law enforcement for purposes of locating the child. (Caretaker missing means that the child's whereabouts were unknown to the child's primary caretaker, with the result that the caretaker was alarmed for at least 1 hour and tried to locate the child.)

\section{Methodology}

The NISMART-2 data on the two types of nonfamily abductions are the product of different methodologies. Victims of the less serious nonfamily abductions are numerous enough to be estimated through a householdsampling procedure and were thus identified by interviewing caretakers and youth through a national telephone survey of households. Victims of stereotypical kidnappings, however, are rare and therefore difficult to estimate through household sampling without conducting an enormous and prohibitively expensive survey. Thus, a different methodology, one that involved a survey of law enforcement agencies throughout the United States, was used to ensure an accurate estimate of the number of stereotypical kidnapping victims. The research team assumed that almost all stereotypical kidnappings were serious enough to be reported to and recorded by law enforcement. The sidebar on methodology (page 5) explains how the estimates were derived.

Adult Caretaker and Youth Household Surveys. The Household Survey interviews were designed to screen for potentially countable NISMART-2 episodes, collect demographic data on the household and its members, conduct indepth followup interviews specific to each type of episode being researched, and collect data on any actual or attempted sexual assaults that may have occurred during the episode. The Household Surveys screened for potential family abductions, nonfamily abductions, runaway/thrownaway episodes, and other missing child episodes that resulted from children being lost or injured or from benign misunderstandings.

Respondents were administered a set of 17 episode screening questions to determine their eligibility for an indepth followup interview designed to collect detailed data on each type of episode. The adult episode screening questions that led to a nonfamily abduction followup interview are presented in the sidebar on page 6 . The youth version, administered to youth between the ages of 10 and 18 , was essentially the same.

Law Enforcement Study. This study collected information from a nationally representative sample of law enforcement agencies by interviewing the key investigating officer in each of the qualifying stereotypical kidnapping cases handled by that agency in 1997. The purposes of the Law Enforcement Study (LES) were to estimate the number of child victims of stereotypical kidnappings during the study year, to learn about the investigation burden of such cases for law enforcement agencies, to describe the circumstances of these stereotypical kidnappings and the characteristics of their perpetrators and victims, and to determine the outcomes.

\section{Resullts}

An estimated 58,200 children were abducted by a nonfamily perpetrator in the study year, including an estimated 115 victims of stereotypical kidnappings (table 1). As expected, the number of stereotypical kidnapping victims reported in the Household Surveys was not sufficient to 


\section{Examples of NISMART-2 Nonfamily Abductions}

\section{Nonfamily Abduction Examples That Are Not Stereotypical Kidnappings}

A 17-year-old girl's ex-boyfriend forced her from her parked car, threw her into his car, and took her to a shopping mall parking lot where he detained her by force for 4 hours. The girl's mother became alarmed when her daughter's employer called to see why the girl had not shown up for work. Upon receiving the call from the employer, the mother drove to the girl's workplace, saw her abandoned car, then called the police to locate the missing child. (Caretaker and reported missing)

A 14-year-old boy was hunting in a park when a strange man appeared, claiming that the boy was trespassing on his property. This was not the case. Nonetheless, the "property owner" detained the boy at gunpoint and forced him to remove his outer garments to see if he had any weapons other than his shotgun. Then, the "property owner" forced the boy into the woods at gunpoint. When the boy did not return home on time, the caretaker became alarmed and tried to find him. When the boy returned home, the police and the park warden were contacted. (Caretaker missing)

A 4-year-old boy was taken on a 20 -mile joyride by the schoolbus driver after the rest of the children had been dropped off at their homes. No force or threat was used to transport or detain the child; however, the bus driver concealed the child's whereabouts. When the child did not come home at the usual time, the alarmed caretaker called the school and bus company to locate the child. Then, upon finding out where the child was, the caretaker contacted the police to recover the child. This episode lasted 7 hours. (Caretaker missing)

A babysitter refused to let three children, ages 4,7 , and 10 , go home until she was paid for prior babysitting. The babysitter detained the children against their will and did not allow the alarmed caretaker to contact the children because she did not answer the phone. When the babysitter finally answered the phone, she lied, telling the caretaker that the children were on their way home. The caretaker called the police to recover the children from a known location. (Not missing)

A 17-year-old girl was on a date with a long-term acquaintance (a 17-year-old boy) who took her in a car to a dark, secluded area on a mountain, where he tried to rape her. The girl was detained by force and sexually assaulted. In this case, the caretaker was not concerned nor did she call the police because she figured the girl would come home. (Not missing)

A 13-year-old girl was hanging out with "bad kids" (according to her caretaker) and grabbed by a 17-year-old male friend (not a romantic friend) who tried to sexually assault her. The perpetrator used threats and force to take her to his home, where he used force to detain her. The police were called for a reason other than to locate or recover the child. (Not missing)
A 9-year-old girl was lured into the perpetrator's camper trailer with an offer of candy. The perpetrator, a 35-yearold male, detained the child by force in the trailer for an hour while he sexually assaulted her. The police were called for a reason other than to locate or recover the child, and the perpetrator was arrested. (Not missing)

A 15-year-old girl was lured by a friend into the hallway at school, then pushed 25 feet into the boys' bathroom by some older boys who detained her by force and sexually assaulted her before she managed to escape screaming. The school contacted the police to report the crime and the boys were arrested. (Not missing)

A 10 -year-old girl was lured with candy and money by an 85-year-old male neighbor and long-term acquaintance into his home, where he sexually assaulted the child. The caretaker did not contact police because she said she had no concrete evidence and the child was not injured. (Not missing)

A 17-year-old boy was with a very recent male acquaintance at the perpetrator's home. The perpetrator detained the boy for an hour by force and sexually assaulted him. The police were not called because the caretaker did not find out about the episode until more than a year later. (Not missing)

A 17-year-old girl was forcibly detained and sexually assaulted in a parking lot at a football game by a 25-year-old male who was an ordinary friend and long-term acquaintance. The police were not called because the girl did not tell her parents. The respondent in this interview was the victim's older sister. (Not missing)

\section{Examples of Stereotypical Kidnappings}

A 12-year-old girl left home for a short jog, telling her mother she would be back in 20 minutes. That was the last time she was seen alive. The police were called to report her disappearance. A few weeks later, the body of the victim was discovered accidentally by a man and his son, who were walking their dog. Police believed that the perpetrator used a blitz attack and grabbed the victim while she was jogging to sexually assault her. (Caretaker and reported missing)

Two 14-year-old girls were spending the night together. In the evening, they walked 12 blocks to a store. The girls were walking back to the house when a car pulled up and two men jumped out, grabbed them, and forced them into the car. One perpetrator had a knife, and told the victims he would kill them. The perpetrators drove to a closed State park. One of the victims was taken out of the car and sexually assaulted. When the girls did not return that night, the police were contacted to report the girls missing. The next morning, a county deputy on a routine patrol of the closed park noticed the car and investigated. He rescued the two girls and apprehended one of the perpetrators. (Caretaker and reported missing) 


\section{Methodology}

The nonfamily abduction estimates are based on the combination of nonfamily abduction data collected in the NISMART-2 Household Surveys and the stereotypical kidnapping data collected in the Law Enforcement Study (LES).

The Household Surveys were conducted during 1999 using computer-assisted telephone interviewing methodology to collect information from a national sample of households. A total of 16,111 interviews were completed with an adult primary caretaker, resulting in an 80-percent cooperation rate among eligible households with children and a 61-percent response rate. The total number of children included in the Household Survey of Adult Caretakers was 31,787 . Each primary caretaker who completed an interview was asked for permission to interview one randomly selected youth in the household ages 10-18. Permission was granted to interview 60 percent of the randomly selected youth, and 95 percent completed an interview, yielding 5,015 youth interviews.

Both the adult and youth survey data were weighted to reflect the Census-based U.S. population of children. (For details about the weighting procedure and variance estimation, see OJJDP's forthcoming NISMART-2 Household Survey Methodology Technical Report.)

The Household Surveys are limited because they may have undercounted children who experienced episodes but were living in households without telephones or were not living in households during the study period, including street children and homeless families. Although these are not large populations in comparison to the overall child population, they may be at risk for episodes.

The LES sample included all law enforcement agencies serving a nationally representative sample of 400 counties. Counties were selected with probabilities proportional to the size of their child populations. There were 400 county sheriff departments and 3,765 municipal police departments serving these counties, for a total sample of 4,165 law enforcement agencies.

Data were collected in two phases. In the first phase, a mail survey was sent to all law enforcement agencies in the sample. This questionnaire asked whether the agency had any stereotypical kidnappings open for investigation during the 1997 calendar year. The response rate for the mail survey was 91 percent. Agencies that reported any stereotypical kidnappings in the mail survey were contacted again in the second phase of data collection, and an extensive followup telephone interview was conducted with the key investigating officer for each case. Data collection was completed for 99 percent of the cases targeted for followup interviews.
Incorporating both phases of the LES, the combined response rate for the study was 91 percent. LES case weights were developed to reflect the probability of the agency and case having been included in the sample and to adjust for nonresponse and refusals.

Data from the Household Surveys and LES were integrated to construct unified estimates of the number of child victims of nonfamily abductions. Two key principles guided this integration:

Principle 1: To combine episode data within a study, each sampled child could be counted only once in the unified estimate.

Principle 2: To unify episode data across studies, a given subgroup of children could be represented by the data from one study only.

Beginning with the data from the Household Survey of Adult Caretakers, children who qualified as having been victims of nonfamily abduction on the basis of any countable episode other than a stereotypical kidnapping were entered into the unified estimate of nonfamily abducted children. In accordance with the first principle previously described, children who were reported as victims of nonfamily abduction in both the adult and youth interviews were counted only once in the unified estimate. In accordance with the second principle previously described, only the LES data were used as the source for the stereotypical kidnapping estimates because no reliable estimate could be developed from the Household Surveys for this rare subset of nonfamily abducted children.

As noted at the beginning of the Bulletin, the NISMART-2 Household Surveys and Law Enforcement Study spanned the years 1997-99, and all data in each of the individual component studies were collected to reflect a 12-month period. The study years are 1999 for the Household Surveys and 1997 for the Law Enforcement Study. Because the vast majority of nonfamily abducted children were from the studies concentrated in 1999, the annual period referred to in this Bulletin is 1999.

A detailed description of the unified estimate methodology is provided in OJJDP's forthcoming Unified Estimate Methodology Technical Report, and details on the findings of the LES are provided in OJJDP's forthcoming Research Report, Stereotypical Kidnappings: National Estimates and Case Profiles. 


\section{Household Survey of Adult Caretakers: Nonfamily Abduction Episode Screening Questions}

The Household Survey of Adult Caretakers episode screening questions used to determine whether a nonfamily abduction followup interview would be conducted are presented below.

- Was there any time when anyone tried to take [this child/any of these children] away from you against your wishes?

- Was there any time when anyone tried to sexually molest, rape, attack, or beat up [this child/any of these children]?

- In the past 12 months, has anyone attacked or threatened [this child/any of these children] in any of these ways:

- With any weapon, for instance, a gun or knife?

- With anything like a baseball bat, frying pan, scissors, or stick?

- By something thrown, such as a rock or bottle?

- Including any grabbing, punching, or choking?

- Any rape, attempted rape, or other type of sexual attack?

- Any face-to-face threats?

- Any attack or threat or use of force by anyone at all?

Something that happens to some children these days is that adults or other youth try to force or trick them into doing something sexual. This includes trying to touch the child's private parts or trying to make the child touch or look at the other person's private parts. Children report that these kinds of things happen with people they know well or trust, such as teachers or relatives.

- In the past 12 months, has there been a time when an older person, such as an adult, an older teenager, or a babysitter, deliberately touched or tried to touch your child's private parts or tried to make your child touch or look at their private parts when your child did not want it?

- [Has/have] [this child/any of these children] been forced or coerced to engage in unwanted sexual activity by someone [he/she/they] did not know before, a casual acquaintance, or someone [he knows/she knows/they know] well?

- Has anyone ever kidnapped or tried to kidnap [this child/any of these children]?
Table 1: Estimates of Nonfamily Abducted Children

Category Estimate $\begin{gathered}95 \% \text { Confidence } \\ \text { Interval* }\end{gathered}$ Percent

All nonfamily
abduction
victims

$58,200 \quad(24,100-92,400)$

Caretaker missing $^{\dagger}$

$33,000 \quad(2,000-64,000)$

Reported missing ${ }^{\ddagger}$

$12,100^{\S}$

$(<100-31,000)$

Stereotypical

kidnapping

victims

115

$(60-170)$

100

Caretaker/reported

missing?

90

$(35-140)$

78

Note: Estimates for caretaker missing and reported missing should not be summed because the categories are not mutually exclusive.

* The 95-percent confidence interval indicates that if the study were repeated 100 times, 95 of the replications would produce estimates within the ranges noted.

† Whereabouts unknown to caretaker, caretaker was alarmed and tried to locate child.

‡ Missing children whose parents or caretakers have reported them to authorities in order to help locate them.

$\S$ Estimate is based on an extremely small sample of cases; therefore, its precision and confidence interval are unreliable.

I Stereotypically kidnapped children were classified as reported missing if the police were notified by someone who discovered the child was missing or someone who witnessed the abduction. Among the stereotypical kidnapping victims, caretaker missing children are the same children as those reported missing.

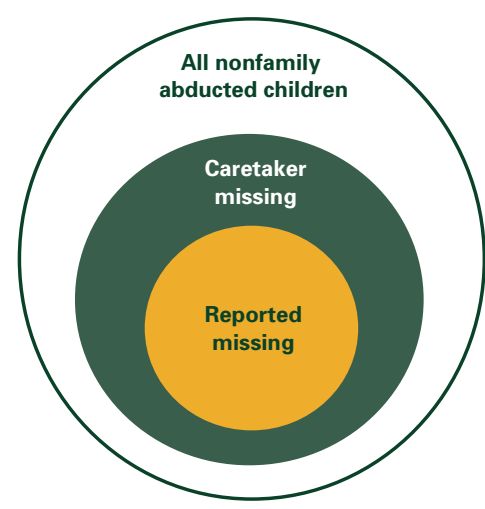

The diagram illustrates the proportional relationship between the total number of nonfamily abducted children and the number of these children who were caretaker missing and reported missing. It also shows that children who were reported missing are a subset of those who were caretaker missing. 
produce a reliable estimate of their incidence from that source; therefore, all of the data on this subset of victims come from the LES. In the following discussion, which describes all nonfamily abducted children and the subset of child victims of stereotypical kidnappings, those who experienced stereotypical kidnappings are such a small part of the overall category that they barely influence the aggregate patterns.

According to the NISMART-2 definitions, an estimated 57 percent of all child victims of nonfamily abduction (approximately 33,000 children) were missing from their caretakers in the study year. (See table 1 and the accompanying diagram.) Moreover, an estimated 21 per-

cent of all nonfamily abducted children (approximately $12,100)$ were also reported to law enforcement as missing. (Unfortunately, both of these numerical estimates are quite imprecise and could actually be quite a bit smaller or larger because they are based on very small numbers of cases.) Stereotypically kidnapped children in this study were considerably more likely to be caretaker missing and reported as missing compared with nonfamily abducted children overall, with 78 percent of victims of stereotypical kidnappings reported missing. Because the estimates are based entirely on cases reported to law enforcement, the estimate for the number of stereotypically kidnapped children who were missing from their caretakers does not include any children who were kidnapped and not reported to the police. Such children may exist; however, given the seriousness of stereotypical kidnapping episodes, they are presumed to be extremely rare.

Recent, notorious nonfamily abductions have often involved quite young children, such as 5-year-old Samantha Runnion of Orange County, CA. However, young children, despite the publicity accorded their abduction, are not the most frequent victims of nonfamily abduction. Eighty-one percent of nonfamily abducted children and 58 percent of stereotypical kidnapping victims were 
Table 3: Characteristics of Nonfamily Abduction Perpetrators

\begin{tabular}{|c|c|c|}
\hline $\begin{array}{l}\text { Characteristic of } \\
\text { Perpetrator }\end{array}$ & $\begin{array}{c}\text { Percent of All } \\
\text { Nonfamily Abduction } \\
\text { Victims }(n=58,200)\end{array}$ & $\begin{array}{c}\text { Percent of } \\
\text { Stereotypical } \\
\text { Kidnapping } \\
\text { Victims }(n=115)\end{array}$ \\
\hline
\end{tabular}

Identity of main perpetrator

Friend

Long-term acquaintance

Neighbor

Authority person

Caretaker or babysitter

Stranger

Slight acquaintance

Someone else

More than one perpetrator

Yes

No

No information

Main perpetrator's gender

Male

75

86

Female

No information

Main perpetrator's age (years)

13-19

$25^{*}$

21

20-29

$42 *$

36

30-39

$12 *$

$16^{*}$

40-49

50-89

No information

$5 *$

$<1^{*}$

* Estimate based on too few sample cases to be reliable.

${ }^{\dagger}$ By definition, stereotypical kidnappings are limited to cases involving strangers and slight acquaintances.
Black children appear to be disproportionately represented among the victims of nonfamily abductions but not among stereotypical kidnapping victims. However, this disproportion is not large enough to exclude the possibility that it is a result of random factors in the sample selection. For similar reasons, the absence of any nonfamily abducted children from the Northeast cannot be considered conclusive evidence of lower rates in that region.

Because kidnapping prevention focuses on the danger of strangers, it may be surprising that the majority of nonfamily abduction victims (53 percent) are abducted by persons known to the child: 38 percent of nonfamily abducted children were abducted by a friend or long-term acquaintance, 5 percent by a neighbor, 6 percent by persons of authority, and 4 percent by a caretaker or babysitter (table 3 ). Strangers abducted 37 percent of the nonfamily abduction victims, and slight acquaintances /considered similar to strangers and including persons who were known but seen infrequently or who may have recently befriended a child or family in order to abduct the child) abducted 8 percent. Stereotypical kidnappings, consistent with the most publicized nonfamily abduction cases, are limited by definition to cases perpetrated by strangers and slight acquaintances.

About 1 in 5 victims of nonfamily age 12 or older (table 2). Nonfamily abduction victims overall were particularly concentrated among the oldest groups, with 59 percent being 15-17 years old.

Girls were the predominant victims of nonfamily abductions overall and of stereotypical kidnappings as well (65 percent and 69 percent, respectively), reflecting the frequency of sexual assault as a motive for many nonfamily abductions. abductions (21 percent) and almost half the victims of stereotypical kidnappings (48 percent) were abducted by multiple perpetrators (table 3). In instances of multiple perpetrators, episodes were classified according to the child's relationship with the most closely related perpetrator. Thus, an abduction by a babysitter and her boyfriend, who was a stranger to the child, was classified 
Table 4: Characteristics of Nonfamily Abductions

\begin{tabular}{lcc}
$\begin{array}{l}\text { Characteristic of } \\
\text { Episode }\end{array}$ & $\begin{array}{c}\text { Percent of All } \\
\text { Nonfamily Abduction } \\
\text { Victims }(\boldsymbol{n}=\mathbf{5 8 , 2 0 0 )}\end{array}$ & $\begin{array}{c}\text { Percent of } \\
\text { Stereotypical } \\
\text { Kidnapping } \\
\text { Victims ( } \boldsymbol{n}=\mathbf{1 1 5})\end{array}$ \\
\hline $\begin{array}{l}\text { Child's location prior to } \\
\text { episode }\end{array}$ & $5^{*}$ & 16 \\
Own home or yard & $18^{*}$ & $3^{*}$ \\
Other home or yard & $32^{*}$ & 40 \\
Street, car, or other vehicle & $25^{*}$ & $14^{*}$ \\
Park or wooded area & $14^{*}$ & $\mathrm{n} / \mathrm{a}^{\dagger}$ \\
Other public area & $5^{*}$ & $2^{*}$ \\
School or daycare & $<1^{*}$ & $8^{*}$ \\
Store, restaurant, or mall & $<1^{*}$ & $9^{*}$ \\
Other location & $<1^{*}$ & $8^{*}$ \\
No information & & 95 \\
Other episode characteristics & 70 & 83 \\
Child was taken or moved & $35^{*}$ & \\
Child was detained &
\end{tabular}

* Estimate is based on too few sample cases to be reliable.

${ }^{\dagger} \mathrm{n} / \mathrm{a}=$ not available.

Table 5: Details Related to the Movement of Nonfamily Abducted Children

\begin{tabular}{lcc} 
Characteristic of & $\begin{array}{c}\text { Percent of All } \\
\text { Nonfamily } \\
\text { Abduction } \\
\text { Eictims }(\boldsymbol{n}=\mathbf{4 0 , 6 0 0})^{*}\end{array}$ & $\begin{array}{c}\text { Percent of } \\
\text { Stereotypical } \\
\text { Kidnapping } \\
\text { Victims }(\boldsymbol{n}=\mathbf{1 0 5})^{*}\end{array}$ \\
\hline How child was taken or moved & $37^{\dagger}$ & $\mathrm{n} / \mathrm{a}^{\ddagger}$ \\
Carried & $28^{\dagger}$ & $\mathrm{n} / \mathrm{a}$ \\
By vehicle & $35^{\dagger}$ & $\mathrm{n} / \mathrm{a}$ \\
Walked & $<1^{\dagger}$ & 100 \\
No information & & $\mathrm{n} / \mathrm{a}$ \\
Where perpetrator took child & $45^{\dagger}$ & $\mathrm{n} / \mathrm{a}$ \\
Vehicle & $28^{\dagger}$ & $\mathrm{n} / \mathrm{a}$ \\
Perpetrator's home & $13^{\dagger}$ & $\mathrm{n} / \mathrm{a}$ \\
Building & $11^{\dagger}$ & $\mathrm{n} / \mathrm{a}$ \\
Outside area & $2^{\dagger}$ & 100 \\
Other & $<1^{\dagger}$ & \\
No information & & $14^{\dagger}$ \\
Child was moved more & & 86 \\
than 50 miles & $<1^{\dagger}$ & \\
Yes & 100 & \\
No & &
\end{tabular}

* Percentages are computed from a baseline of the number of children who were moved.

${ }^{\dagger}$ Estimate is based on too few sample cases to be reliable.

$\neq \mathrm{n} / \mathrm{a}=$ not available as an abduction by a babysitter. Counting only the main perpetrators (and not the accomplices), 25 percent of the nonfamily abduction victims and 7 percent of the stereotypical kidnapping victims were abducted by females. Perpetrators in their twenties were the main abductors of 42 percent of all nonfamily abducted children and of 36 percent of children who were stereotypically kidnapped. Teenagers abducted 25 percent of all nonfamily abducted children.

Homes or yards were the origination point in only a minority of the abductions of all nonfamily abducted children (23 percent) and of those who were stereotypically kidnapped (19 percent) (table 4). Instead, streets, parks or wooded areas, and other public areas (i.e., generally accessible spaces) were the places from which children were typically abducted. While most of the nonfamily abducted children were moved or taken, 35 percent were detained in an isolated location for at least an hour. The majority of stereotypical kidnapping victims were detained in addition to being moved or taken.

When children were moved, the most common modes of conveyance were carrying the child, taking the child in a vehicle, and walking with the child (table 5). Most children were taken into vehicles (45 percent) or to the perpetrator's home (28 percent) (table 5 ). Fourteen percent of the stereotypically kidnapped children were moved more than 50 miles. 
Table 6: Additional Crime Elements in Nonfamily Abductions

\begin{tabular}{lcc}
$\begin{array}{l}\text { Characteristic of } \\
\text { Episode }\end{array}$ & $\begin{array}{c}\text { Percent of All } \\
\text { Nonfamily Abduction } \\
\text { Victims }(\boldsymbol{n}=\mathbf{5 8 , 2 0 0})\end{array}$ & $\begin{array}{c}\text { Percent of } \\
\text { Stereotypical } \\
\text { Kidnapping } \\
\text { Victims }(\boldsymbol{n}=\mathbf{1 1 5})\end{array}$ \\
\hline $\begin{array}{l}\text { Perpetrator sexually } \\
\text { assaulted child }\end{array}$ & 46 & 49 \\
$\begin{array}{l}\text { Perpetrator physically } \\
\text { assaulted child }\end{array}$ & $31^{*}$ & 33 \\
$\begin{array}{l}\text { Perpetrator robbed child } \\
\text { Perpetrator used a weapon }\end{array}$ & $7^{*}$ & 20 \\
Perpetrator demanded ransom & $40^{*}$ & 49 \\
\hline
\end{tabular}

* Estimate is based on too few sample cases to be reliable.

Weapons were involved in abducting 40 percent of all nonfamily abduction victims and 49 percent of stereotypical kidnapping victims. Knives and guns were both frequently used. Ransom was demanded for 4 percent of all nonfamily abducted children and 5 percent of the subset who were stereotypically kidnapped.

A considerable quantity of information on the exact duration of the episodes was missing ( 32 percent of all nonfamily abducted children and 18 percent of stereotypical kidnapping victims) (table 7). Among those children with

Criminal assaults were a motive in most of the nonfamily abductions (table 6). Close to half of all nonfamily abduction victims and stereotypical kidnapping victims were sexually assaulted, while about a third were otherwise physically assaulted. Seven percent of the nonfamily abduction victims and 20 percent of the stereotypical kidnapping victims were robbed. data on episode duration, 29 percent experienced nonfamily abductions that lasted 2 hours or less, and 10 percent had abductions that lasted 24 hours or more (table 7).

Stereotypical kidnappings were defined as episodes lasting overnight (unless there was a homicide, a ransom, or an intent to keep or transport the child 50 miles or more), so it is noteworthy that only 10 percent of stereotypical kidnapping victims had episodes lasting 24 hours or more. Only a very small minority (4 percent) of victims of the most serious stereotypical kidnappings had abductions that were not resolved at the time of data collection.

Nonetheless, 40 percent of stereotypical kidnapping victims were killed, in addition to the 4 percent who were still missing. An additional 32 percent of children who were stereotypically kidnapped received injuries requiring medical attention.

For 53 percent of all nonfamily abduction victims, police were not contacted about the episode for any reason, not even to report the crime (table 8). The reasons for not reporting suggest that some portion of these nonfamily abductions were not thought to involve serious threats to the child. 
The seasonal distribution of nonfamily abductions and stereotypical kidnappings indicates only that they occur less frequently in winter (table 9).

\section{Implications}

When, in the wake of notorious kidnappings, parents and reporters clamor for information about the risk children face for such heinous crimes, the best answer currently available based on the data from this study is that an estimated 115 children and youth were the victims of a stereotypical kidnapping in the study year, and that the true number was somewhere between 60 and 170 (this range represents the 95-percent confidence interval around the estimate). This estimate is consistent with the Federal Bureau of Investigation's (FBI's) estimates of the number of abductions by strangers in which, because of their seriousness or duration, Federal law enforcement becomes involved (M. Heimbach, personal communication, August 22, 2002).

The larger number identified in this study, the 58,200 nonfamily abduction victims, represents an estimate of the number of child victims of crimes that meet the legal definition of abduction by a nonfamily perpetrator. Most children's nonfamily abduction episodes do not involve elements of the extremely alarming kind of crime that parents and reporters have in mind (such as a child's being killed, abducted overnight, taken long distances, held for ransom or with the intent to keep the child) when they think about a kidnapping by a stranger.

There was some kind of police contact regarding 47 percent of the nonfamily
Table 8: Police Contact for Nonfamily Abductions

\begin{tabular}{|c|c|c|}
\hline $\begin{array}{l}\text { Characteristic of } \\
\text { Episode }\end{array}$ & $\begin{array}{c}\text { Percent of All } \\
\text { Nonfamily Abduction } \\
\text { Victims ( } n=58,200 \text { ) }\end{array}$ & $\begin{array}{c}\text { Percent of } \\
\text { Stereotypical } \\
\text { Kidnapping } \\
\text { Victims }(n=115)\end{array}$ \\
\hline
\end{tabular}

Any police contact

Yes

No

$47 *$

100

$53 *$

$\mathrm{n} / \mathrm{a}^{\dagger}$

Reason police were not contacted $^{\ddagger}$

Expected child to return

Lack of evidence

Caretaker informed too long after abduction

Child wanted to protect perpetrator

Caretaker not told about abduction

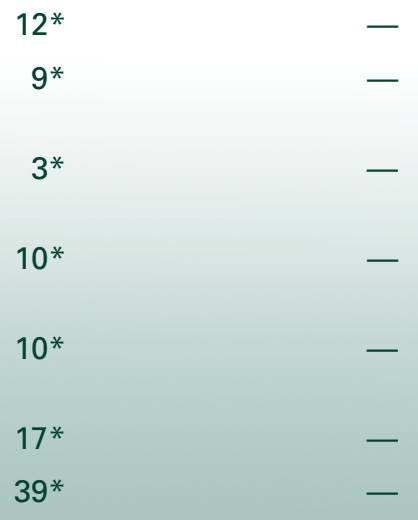

Episode was not serious enough

$39 *$

* Estimate is based on too few sample cases to be reliable.

$\dagger_{\mathrm{n}} / \mathrm{a}=$ not available

₹ Percentages are computed from a baseline of 30,800 , the number of children with no police contact.

Table 9: Season of Nonfamily Abductions

\begin{tabular}{lcc} 
Season of Episode & $\begin{array}{c}\text { Percent of All } \\
\text { Nonfamily Abduction } \\
\text { Victims }(\boldsymbol{n}=\mathbf{5 8 , 2 0 0})\end{array}$ & $\begin{array}{c}\text { Percent of } \\
\text { Stereotypical } \\
\text { Kidnapping } \\
\text { Victims }(\boldsymbol{n}=\mathbf{1 1 5})\end{array}$ \\
\hline Winter & $15^{*}$ & $9^{*}$ \\
Spring & $36^{*}$ & 28 \\
Summer & $30^{*}$ & 29 \\
Fall & $19^{*}$ & 33 \\
No information & $<1^{*}$ & $1^{*}$
\end{tabular}

* Estimate is based on too few sample cases to be reliable. 
abducted children, either to report the child as missing or for other reasons. However, in 53 percent of cases, there was no police contact. Most caretakers who did not contact the police expected the child to return or did not think the episode was particularly serious, and some caretakers were never told about the episode (as revealed by the youth who were interviewed).

In 1988, NISMART-1 estimated that stereotypical kidnappings numbered between 200 and 300 annually (Finkelhor, Hotaling, and Sedlak, 1990). Comparing the new NISMART-2 estimates with these older estimates, people may be inclined to conclude that there has been a substantial decline in stereotypical kidnappings during the past decade. Unfortunately, such a clear-cut conclusion is not scientifically justified by the current evidence because the imprecision of the estimates and differences in the methodologies do not allow it.

The higher estimate of NISMART-1 was obtained using a methodology that differs from the current methodology, and, unlike the current estimate, its precision could not be accurately determined. The actual number of stereotypical kidnappings in the NISMART-1 study year may, in fact, be within the NISMART-2 confidence interval, and thus not significantly different from the NISMART-2 estimate.

Nonetheless, stereotypical kidnappings do not appear to be any more frequent in 1999 than in 1988. Moreover, despite using different methodologies, NISMART-1 and NISMART-2 yield estimates of the same order of magnitude (in the hundreds rather than in thousands), reinforcing confidence that the estimates for both years are in the true range.

The possibility that stereotypical kidnappings have declined is supported by declining rates of juvenile-victim homicides and of sexual and aggravated assaults in the 1990s. Such crimes include instances of and provide the context for many kidnappings by strangers. However, the current data, given their limitations, cannot be used to confirm this possibility.

Comparison of NISMART-1 and NISMART-2 findings with regard to the more general category of nonfamily abduction may also cause confusion. NISMART-1 estimated that approximately 3,200-4,600 children qualified for a "legal definition" nonfamily abduction known to police, which seems markedly smaller than the estimate of 58,200 victims of nonfamily abduction from NISMART-2.

Although the definitions used in NISMART-1 and NISMART-2 were virtually the same, the NISMART-1 estimate included only nonfamily abductions known to police exclusively and was calculated from a review of police records in which researchers looked for elements of abduction in written case material about reported crimes. The estimate was believed at the time to be a serious undercount because police records so frequently failed to note elements of forced movement or detention in their accounts of crimes like sexual assault. In contrast, the NISMART-2 estimate is based on accounts by victims and their caretakers who were asked systematically in a national survey about possible elements of abduction in the course of crime victimizations. Slightly more than half of the estimated 58,200 nonfamily abducted children from NISMART-2 were not even reported to the police.

Nonetheless, in trying to interpret this new and considerably higher estimate of the number of nonfamily abducted children, several considerations should be kept in mind. First, because the new estimate is based on victim accounts rather than police records, it inherently involves a much lower threshold of seriousness. Moreover, the definition of nonfamily abduction used in NISMART involves modest amounts of coerced movement or detention that are present in many violent and sexual crimes. When children suffer more than 2 million violent crimes each year, including more than 100,000 cases of sexual assault and sexual abuse, it is quite reasonable that tens of thousands of these crimes involve coerced movement and detention (Crimes against Children Research Center, 1999|. Finally, however, even phenomena that occur to tens of thousands of children are hard to estimate with surveys the size of those in NISMART-2. As a result, there is more imprecision and margin of error in the nonfamily abduction estimate than in any of the other NISMART-2 estimates.

The NISMART-2 findings reinforce the 1988 study's conclusion that teenage girls are the most frequent targets of nonfamily abductions and stereotypical 
kidnappings. To some extent, this finding contrasts with the image drawn from media accounts of the abduction of very young children such as Adam Walsh and Samantha Runnion. Perhaps the innocence and vulnerability of younger children ensure more publicity and greater notoriety for these cases. Nonetheless, in planning strategies for preventing and responding to nonfamily abductions, it is important to keep efforts from being misdirected by the stereotype of the preteen victim. In fact, the vulnerability of teens needs to be a central principle guiding such planning.

Strategies for prevention and intervention also need to recognize that acquaintances play a greater role than strangers do in abductions that occur outside the family. In the current study, more than half of the nonfamily abduction victims were abducted by persons known to the child. If parents and law enforcement assume that abduction is an element only in crimes committed by strangers, they may fail to provide appropriate prevention information to young people. More attention needs to be given to the motives and dynamics of crimes involving abductions by perpetrators known to the child.

The NISMART-2 results reinforce the generally well known fact that sexual assault is the motive for a considerable percentage of nonfamily abductions. This suggests the importance and usefulness of combining sexual assault prevention strategies and abduction prevention strategies as a way to reduce the rates of both crimes. Recent declines in rates of sexual abuse during the 1990s (Jones and Finkelhor, 2001) point to the possible effectiveness of recent sexual assault prevention strategies, including public awareness, educational programs, and aggressive prosecution to increase general and specific deterrence.

The considerable interest in statistics on nonfamily abduction raises obvious questions about how statistics can be obtained more regularly and systematically. Part of the solution to this problem may come with the full implementation of the National Incident-Based Reporting System (NIBRS), which is being introduced by the FBI to supplant the Uniform Crime Reporting Program (UCR) as the source of national information about crimes known to police. NIBRS, unlike its predecessor, allows police to indicate when abduction occurs alone or in connection with other crimes.

When NIBRS is fully implemented nationally, it will be able to generate annual estimates of the number of children, known to the police, who are abducted not only by nonfamily perpetrators but also by family members. Unfortunately, only 20 States contributed to NIBRS as of 2000, and its national implementation is unlikely to be complete for another decade. The analysis of these NIBRS data has already yielded some useful conclusions (Finkelhor and Ormrod, 2000), such as the large number and distinctive features of acquaintance kidnapping. However, the NIBRS data are not yet of use in calculating national incidence or tracking national trends.

One question pertaining to NIBRS in connection with child abduction data is how quickly police, who have not had to record the abduction element of crimes systematically under UCR, are going to do so in NIBRS data collection. An additional limitation of NIBRS is that it does not collect the kind of data that would facilitate estimating the incidence of stereotypical kidnapping, as defined by NISMART. To do this, NIBRS would have to collect more data on specific crime episode characteristics, such as the duration of the episode and the distance victims were taken.

The National Crime Information Center (NCIC), to which local police report missing children for whom they are searching, may present an opportunity to track the incidence of stereotypical kidnappings more regularly. At the present time, the NCIC system is not used for statistical or data-gathering purposes.

Finally, conducting studies such as those reported in this Bulletin on a more regular basis would enhance the availability of timely statistics on abducted and missing children.

\section{Endnote}

1. The reference dates for some of the NISMART-2 component studies vary because of a delay caused by pending Federal legislation that, had it passed, would have made it impossible to conduct the National Household Survey of Youth, a key component of NISMART-2. In anticipation of a quick resolution, OJJDP decided to 
proceed with the Law Enforcement Study and the Juvenile Facilities Study because neither involved interviewing youth. Had these 1997 studies been postponed until 1999, it is highly unlikely that those estimates would have been statistically different.

\section{References}

Crimes against Children Research Center. 1999. Fact Sheet. Retrieved September 2002 from www.unh.edu/ ccrc/factsheet.html

Finkelhor, D., Hotaling, G., and Sedlak, A. 1990. Missing, Abducted, Runaway, and Thrownaway Children in America. First Report: Numbers and Characteristics National Incidence Studies. Washington, DC: U.S. Department of Justice, Office of Justice Programs, Office of Juvenile Justice and Delinquency Prevention.

Finkelhor, D., and Ormrod, R.K. 2000. Kidnapping of Juveniles: Patterns From NIBRS. Bulletin. Washington, DC: U.S. Department of Justice, Office of Justice Programs, Office of Juvenile Justice and Delinquency Prevention.
Jones, L., and Finkelhor, D. 2001. The Decline in Child Sexual Abuse Cases. Bulletin. Washington, DC: U.S. Department of Justice, Office of Justice Programs, Office of Juvenile Justice and Delinquency Prevention.

U.S. Census Bureau. 2000a. Monthly Postcensal Resident Population, by Single Year of Age, Sex, Race, and Hispanic Origin (e9899rmp.txt, e9999rmp.txt, and e9900rmp.txt). Web site: eire.census.gov/popest/ archives/national/nat_90s_detail/nat_90s_1.php.

U.S. Census Bureau. 2000b. Population Estimates for the U.S. and States by Single Year of Age and Sex: July 1, 1999 (ST-99-10). Web site: eire.census.gov/popest/ archives/state/st-99-10.php.

This Bulletin was prepared under grant number 95-MC-CX-K004 from the Office of Juvenile Justice and Delinquency Prevention, U.S. Department of Justice, to Temple University.

The Office of Juvenile Justice and Delinquency Prevention is a component of the Office of Justice Programs, which also includes the Bureau of Justice Assistance, the Bureau of Justice Statistics, the National Institute of Justice, and the Office for Victims of Crime.

\section{Acknowledgments}

David Finkelhor, Ph.D., is Professor of Sociology and Director, Crimes against Children Research Center, University of New Hampshire, and Advisor to NISMART-2. Heather Hammer, Ph.D., is a Senior Study Director at the Temple University Institute for Survey Research, Philadelphia, PA, and Principal Investigator of NISMART-2. Andrea J. Sedlak, Ph.D., is Associate Director of Human Services Research at Westat, Inc.; Project Director of the NISMART-2 Unified Estimate, Juvenile Facilities Study, and Law Enforcement Study; and Advisor to the NISMART-2 Household Survey.

Other contributors include Louise Hanson, M.A.S., Senior Study Director at the Temple University Institute for Survey Research and Director of Data Collection for the NISMART-2 Household Surveys; Michael K. Barr, M.A., Associate Study Director at the Temple University Institute for Survey Research; Dana J. Schultz, M.P.P., Policy Analyst at Westat, Inc., Operations Manager of the Juvenile Facilities Study and Law Enforcement Study, and Analyst for the Unified Estimate; Richard Ormrod, Ph.D., Research Professor of Geography at the University of New Hampshire Crimes against Children Research Center; G. Hussain Choudhry, Ph.D., Senior Statistician at Westat, Inc.; Svetlana Ryaboy, Statistician at Westat, Inc.; Monica Basena, Analyst at Westat, Inc.; and Ying Long, Programmer at Westat, Inc.

The authors would also like to extend their appreciation to Barbara Allen-Hagen, Senior Social Analyst at OJJDP and NISMART-2 Program Manager, for her support and guidance in every phase of this project. The authors also thank the many individuals who responded to the NISMART-2 surveys for their cooperation and candor. 


\section{For Further Information}

NISMART Questions and Answers, a fact sheet, offers a straightforward introduction to NISMART-2. It answers anticipated questions-such as What is NISMART? Have abductions by strangers declined or increased? and Why can't I compare NISMART-1 statistics with NISMART-2 statistics? - to help explain NISMART's purpose, methodology, and findings.

The first Bulletin in the NISMART series, National Estimates of Missing Children: An Overview, describes the NISMART-2 component studies and estimating methodology, defines the types of episodes studiednonfamily abduction (including stereotypical kidnapping); family abduction; runaway/thrownaway; missing involuntary, lost, or injured; and missing benign explanation-and summarizes NISMART-2 estimates of missing children.

AII NISMART-related publications are available at OJJDP's Web site, ojjdp.ncjrs.org.

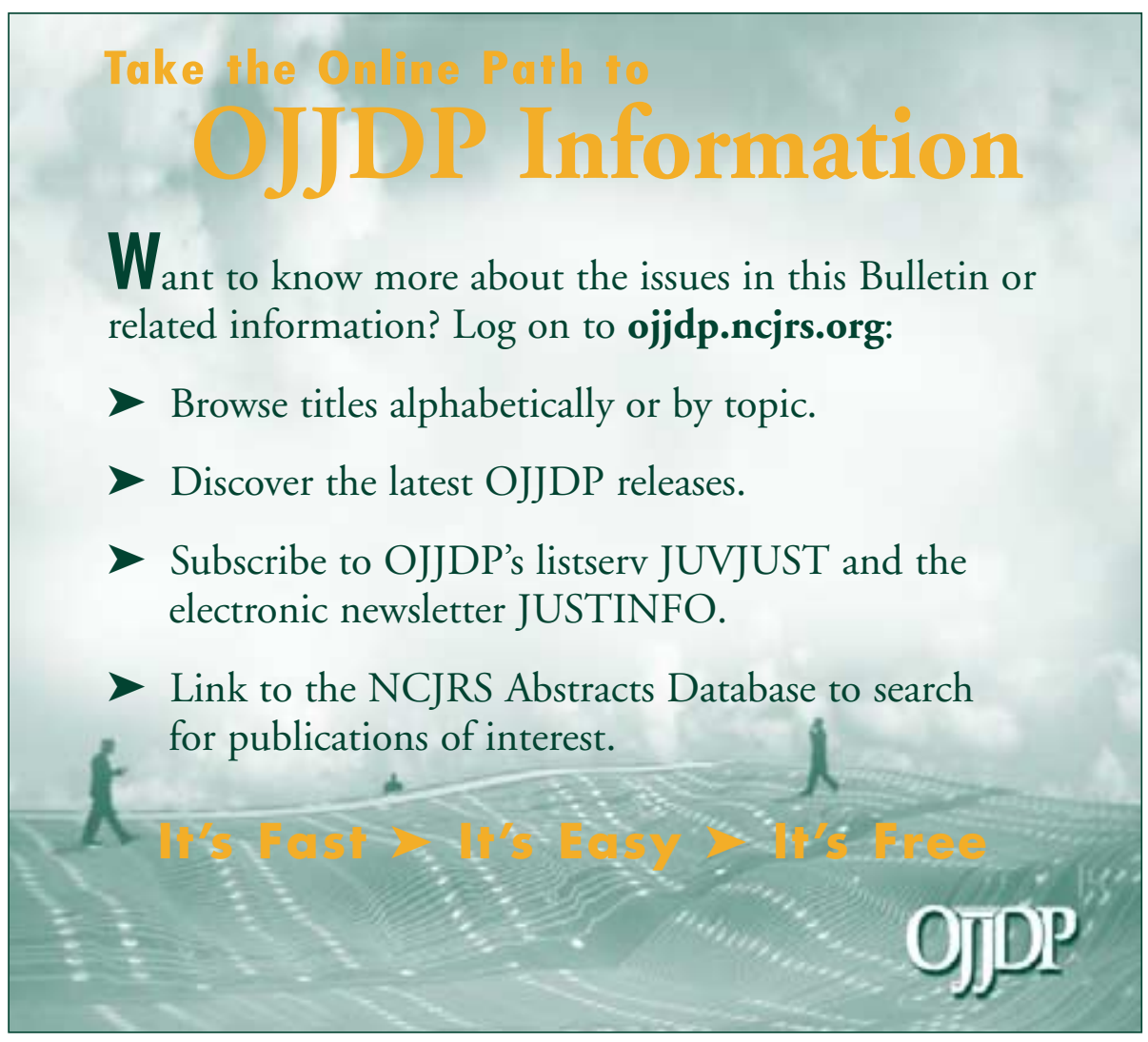


U.S. Department of Justice

PRESORTED STANDARD

Office of Justice Programs

POSTAGE \& FEES PAID DOJ/OJJDP

Office of Juvenile Justice and Delinquency Prevention PERMIT NO. G-91

Washington, DC 20531

Official Business

Penalty for Private Use $\$ 300$ 